\title{
APRENDIZAGEM BASEADA EM PROJETOS: RELEITURA DAS PROPAGANDAS TELEVISIVAS DAS DÉCADAS DE 1980 E 1990 NO BRASIL
}

\author{
PROJECT-BASED LEARNING: RE-READING OF THE TELEVISION \\ ADVERTISEMENTS OF THE DECADES OF 1980 AND 1990 IN BRAZIL
}

\author{
APRENDIZAJE BASADO EN PROYECTOS: RE-LECTURA DE LOS \\ PUBLICIDADES DE TELEVISION DE LAS DÉCADAS DE 1980 Y 1990 EN BRASIL
}

\author{
João Alberto Prado Martin \\ Mestrando em Educação pela Universidade de Araraquara \\ Docente da Etec Cidade do Livro \\ E-mail: joao.martin@etec.sp.gov.br \\ Edmundo Alves de Oliveira \\ Doutor em Sociologia pela Universidade Estadual Paulista \\ Docente da Universidade de Araraquara \\ E-mail: edmundoedmundo@gmail.com
}

\section{RESUMO}

Diante do surgimento das novas práticas de ensino que se observa atualmente, a Aprendizagem Baseada em Projetos tem se destacado por sua praticidade de aplicação e resultados apresentados, principalmente na formação profissional dos cursos de nível técnico. $\mathrm{O}$ presente trabalho teve como objetivo utilizar a Aprendizagem Baseada em Projetos na elaboração de uma sala temática resgatando a história da propaganda no Brasil nas décadas de 1980 e 1990 e concomitantemente a memória de José Abelardo Barbosa de Medeiros, o Chacrinha, como ferramenta de aprendizagem dos alunos. Participaram do estudo quarenta alunos do curso técnico integrado ao médio de administração de uma instituição do interior do estado de São Paulo. Para tanto foram utilizados materiais como projetor multimídia, sistema de som, luzes de LED, bexigas, confetes e serpentinas, notebook, vídeos de propagandas das décadas de 1980 e 1990. Como procedimento, os alunos realizaram um levantamento sobre a propaganda no contexto brasileiro, selecionaram duas propagandas e a partir destas, elaboraram vídeos, tendo eles próprios como atores, fazendo uma releitura para os dias atuais, adaptando a linguagem, vestimentas e contextos culturais. Como resultados, o estudo pode possibilitar aos alunos, a partir da experiência com o projeto desenvolvido, que a história da propaganda forneceu uma compreensão do momento histórico atual, e que as ideias e estratégias utilizadas na década de 1980 e 1990 nas propagandas, ainda estão presentes na atualidade. Conclui-se que a Aprendizagem Baseada em Projetos colocou os alunos na condição de atores do processo, favorecendo a práxis pedagógica quanto à importância de compreender o processo histórico acerca da propaganda.

Palavras-chave: Aprendizagem Baseada em Projetos. Propaganda. Ensino Técnico.

\section{ABSTRACT}

Given the emergence of new teaching practices currently observed, project-based learning has been highlighted by its practicality of application and results presented, mainly in the 
vocational training of technical level courses. The present work aimed to use project-based learning in the elaboration of a thematic room rescuing the history of propaganda in Brazil in the decades of 1980 and 1990 and concomitantly the memory of José Abelardo Barbosa de Medeiros, the Chacrinha, as a learning tool for students. Participated in the study 40 students of the technical course integrated to the medium of administration of an institution in the interior of the state of São Paulo. For this purpose, we used materials such as multimedia projector, sound system, LED lights, balloons, confetti and serpentines, notebook, videos of advertisements from the decades of 1980 and 1990. As a procedure, the students conducted a survey on propaganda in the Brazilian context, selected two advertisements and from these, elaborated videos, having themselves as actors, making a re-reading for the current days, adapting the Language, clothing and cultural contexts. As results, the study can enable students, from the experience with the developed project, that the history of propaganda provided an understanding of the current historical moment, and that the ideas and strategies used in the Decade of 1980 and 1990 in Advertisements, are still present today. It is concluded that project-based learning has placed students in the condition of actors in the process, favoring pedagogical praxis as to the importance of understanding the historical process about propaganda.

Keywords: Project-based learning. Propaganda. Technical education.

\section{RESUMEN}

Antes de la aparición de las nuevas prácticas de enseñanza que actualmente, aprendizaje basado en proyectos ha destacado por su comodidad de aplicación y de resultados, especialmente en la formación de cursos de nivel técnicos. El presente trabajo pretende utilizar el aprendizaje basado en proyectos en el desarrollo de una sala temática de rescatar la historia de la propaganda en Brasil durante los 1980 y 1990 y al mismo tiempo la memoria de José Abelardo Barbosa de Medeiros, el Reunión, como una herramienta de aprendizaje de los estudiantes. Participaron en este estudio 40 estudiantes del curso técnico integradas en el medio de una institución de gestión en el estado de São Paulo en Brasil. Para ambos materiales fueron utilizados como proyector multimedia, sistema de sonido, luces, globos, confeti y serpentinas, portátil, videos anuncios de las décadas de 1980 y 1990. Como procedimiento, estudiantes realizó una encuesta sobre la publicidad en el contexto brasileño, seleccionado dos anuncios y de éstos, preparar videos, teniendo ellos mismos como actores, hacer una relectura a la actualidad, adaptando la lenguaje, contextos culturales y ropas. Como resultado, el estudio puede permitir a los estudiantes, de la experiencia con el proyecto desarrollado, que la historia de la propaganda proporciona una comprensión del momento actual en la historia, y que las ideas y estrategias utilizan en el 1980 y 1990 en la anuncios, están todavía presentes hoy. Se concluye que el aprendizaje basado en proyecto pone a estudiantes en condición de actores en el proceso, favoreciendo a la Praxis pedagógica en cuanto a la importancia de comprender el proceso histórico sobre propaganda.

Palabras clave: Aprendizaje basado en proyectos. Propaganda. Educacion Tecnica.

\section{INTRODUÇÃO}

O processo de ensino em todo o mundo vem sofrendo mudanças com a introdução da tecnologia e de novas metodologias em sala de aula. A sociedade está vivenciando uma 
evolução de tecnologia e comunicação em todos os ambientes de convivência coletiva, está presente na forma em que o indivíduo se locomove, informa, interage e se comunica. Essa realidade não poderia ser diferente no contexto da sala de aula, uma vez que a tecnologia se faz presente no cotidiano do aluno.

A escola deve considerar o perfil discente que há décadas vem se alterando e tornandose tecnológico, porém, esse perfil é, em muitos casos, ignorado pela equipe gestora das unidades escolares, seja por motivos de falta de infraestrutura e investimentos ou pela falta de formação docente para atender essa demanda.

Essa realidade é divergente nas escolas do mundo todo, enquanto algumas insistem em trabalhar com metodologias que já se tornaram obsoletas, outras equipam as salas de aula com o que há de melhor em tecnologia e que muitas vezes, pela falta de docentes capacitados, não são utilizadas como deveriam.

A Educação Profissional e Tecnológica (EPT) que tem como público alvo os alunos que buscam no ensino profissional e profissionalizante uma recolocação rápida no mercado de trabalho vem enfrentando um grande dilema quanto a adaptação das novas metodologias para a sala de aula. Com a introdução da tecnologia também no ambiente de trabalho, as empresas buscam cada vez mais profissionais que saibam trabalhar com equipamentos de alta tecnologia, que saibam lidar com a diversidade e as divergências do trabalho em equipe.

Blikstein (2010) chama a atenção para:

[...] o grande potencial de aprendizagem que é desperdiçado em nossas escolas, diária e sistematicamente, em nome de ideias educacionais obsoletas. [...] É uma tragédia ver, a cada dia, milhares de alunos sendo convencidos de que são incapazes e pouco inteligentes simplesmente porque não conseguem se adaptar a um sistema equivocado (BLIKSTEIN, 2010, p. 3).

Algumas indagações percorrem o ambiente escolar, dentre elas: Qual será o futuro da escola? A Educação a Distância irá extinguir a função do professor? Quais mudanças devem ocorrer no ambiente escolar para que a EPT atenda a demanda do mercado de trabalho atual? Quais seriam as práticas pedagógicas mais adequadas para atender as novas demandas do mercado de trabalho?

Miller, Shapiro e Hilding-Hamann (2008 apud de Barbosa e Moura, 2013) apresentam um cenário do que deve ser a escola nas primeiras décadas do século XXI, um ambiente onde 
a escola tradicional seria transformada em espaços de aprendizagem colaborativa e intensiva, uma visão radical e diferente do modelo convencional, onde o quadro negro e o professor se impõem perante os alunos.

Percebe-se que a escola caminha em busca de novas práticas pedagógicas como forma de proporcionar ao aluno um aprendizado diferenciado e próximo à sua realidade. Alguns fatores impulsionam o sistema educacional a buscar novas propostas de aprendizagem, dentre eles pode-se destacar a globalização e o acesso à informação decorrente do advento da internet, porém um fator é preponderante para essa busca pela inovação, a chegada das chamadas geração Y e Z no mercado de trabalho e principalmente na área educacional.

Para Maurer (2013 apud de Strauss e Howe, 1991) as barreiras geracionais são definidas pelo calendário anual, marcadas pelo ano de nascimento dos indivíduos, encontrando-se dessa forma quatro gerações atuais que compõe a realidade presente no mercado de trabalho e nas instituições de ensino, sendo elas: A Geração Baby Boomers, nascidos entre 1943 e 1960; Geração X, nascidos entre 1961 e 1981; Geração Y, nascidos no início dos anos 1980 a 1990 e a Geração Z, nascidos a partir do início da década de 1990.

A Geração Baby Boomers é chamada dessa forma em função de serem os filhos nascidos após a $2^{\mathrm{a}}$ Guerra Mundial e são caracterizados por um perfil tradicional e ultraconservador, muitos deles já estão fora do mercado de trabalho.

A Geração mais próxima dos Baby Boomers é a Geração X, que assume atualmente no ambiente do trabalho a função dos conservadores deixado pelos Baby Boomers, composta por pessoas com um perfil conservador e com uma pequena base de conhecimento em tecnologia. As últimas pessoas nascidas nessa geração, em 1981, não tinham acesso à internet e o computador pessoal (PC) era algo que começava a ser popularizar sendo acessível a poucas pessoas.

A Geração Y constitui-se pelos filhos da tecnologia, pois nasceram em uma época que a tecnologia se popularizava por todo o mundo. Maurer (2013 apud Toledo, Albuquerque e Magalhães, 2012) colocam esse público como alunos que valorizam o nível de atualização das informações, e que essas precisam ser mais atuais, buscando resultados imediatos.

Por outro lado, a Geração Z, conhecida como as “crianças da era das telas" não conhecem o mundo sem o acesso à internet, citado por Cerreta e Froeming (2011, p. 5) como aqueles que "nunca conceberam o mundo sem computador, chats e telefone celular" e apresentam um perfil antissocial e individualista.

90

RELEDUC | ISE | v. 2 | n. 2 | ago. 2019 
Diante desse cenário surge alguns questionamentos que denotam a realidade enfrentada pelo aluno no ambiente escolar, dentre eles: Como pode uma geração conectada com o mundo estar desconectada em sala de aula? Como podemos não evoluir na educação se tudo o que está a volta do aluno evolui? Nesse sentido surgem as metodologias ativas com a proposta de inovar a ação docente em sala de aula, proporcionando ao aluno autonomia na busca pelo conhecimento e que o mesmo se faça de forma colaborativa.

A metodologia ativa tem o papel de inserir o aluno no processo de ensinoaprendizagem, deixando de ser um agente passivo para ser ativo na construção do conhecimento por meio das análises de problemas. Para Moran e Bacich (2018) metodologias ativas são estratégias de ensino centradas na participação efetiva dos estudantes na construção do processo de aprendizagem, de forma flexível, interligada e híbrida. Ainda, segundo os autores, as metodologias ativas enfatizam ao papel protagonista do aluno, ao seu envolvimento direto, participativo e reflexivo em todas as etapas do processo.

Baseado na visão de Freire (1996), Berbel (2011, p. 29) apresenta uma defesa das metodologias ativas de aprendizagem e diz que "na educação de adultos o que impulsiona a aprendizagem é a resolução de problemas, superação de desafios e a construção de conhecimento novo a partir de conhecimentos e experiências prévias dos indivíduos".

As metodologias ativas de aprendizagem apresentam vários modelos que pode colocar o aluno como protagonista na formação do conhecimento, sendo eles: Aprendizagem Baseada em Problemas (PBL), Aprendizagem Baseada em Projetos (PBL), Peer Instruction (PI), Just-in-Time Teaching (JiTT), Aprendizagem Baseada em Times (TBL), Métodos de Caso, Simulações e o Ensino Híbrido.

Nesse cenário, o surgimento das Tecnologias da Informação e Comunicação (TICs) aparece com um papel fundamental no processo de formação do aluno, oferecendo autonomia e corroborando para a democratização do ensino.

A Aprendizagem Baseada em Projetos é representada pelas siglas PBL, proveniente do termo inglês Problem Basead Learning, é uma metodologia ativa que tem como objetivo apresentar aos alunos um problema inicial ao qual eles precisam resolver de forma colaborativa, entre pares, por um determinado período de tempo.

Para Irala (2005) os temas dos projetos abrangem questões sobre assuntos autênticos do mundo real, o que se espera ao se trabalharem esses projetos é que, durante o processo de pesquisa e investigação coletiva dos temas, os participantes aprendam o conteúdo, obtendo 
fatos e informações necessários para chegarem a conclusões sobre o problema ou questão inicialmente lançada.

Ainda segundo a autora:

\begin{abstract}
A aprendizagem por meio de projetos é um método efetivo para envolver os alunos no processo de aprendizagem. Com essa metodologia, os alunos têm a oportunidade de trabalhar com problemas e questões de relevância para suas vidas, bem como aprender habilidades de colaboração e comunicação, necessárias para seu sucesso na escola e no mundo do trabalho (IRALA, 2005, p. 78).
\end{abstract}

Dessa forma, a Aprendizagem Baseada em Projetos, diferentemente das práticas tradicionais, exige que os alunos utilizem habilidades específicas para o desenvolvimento dos trabalhos, procurando desenvolver aptidões por meio do trabalho em equipe, do gerenciamento do tempo e da colaboração entre os pares.

\title{
2 METODOLOGIA
}

O presente estudo abordou como metodologia a pesquisa descritiva e o estudo de caso, a pesquisa descritiva tem como objetivo descrever um fenômeno, uma população ou experiência. Para Triviños (1987 apud de Oliveira, 2011, p. 21), "o estudo descritivo pretende descrever "com exatidão" os fatos e fenômenos de determinada realidade", de modo que o estudo descritivo é utilizado quando a intenção do pesquisador é conhecer determinada comunidade, suas características, valores e problemas relacionados à cultura.

O estudo de caso tem como propósito reunir informações detalhadas e sistemáticas sobre um fenômeno (PATTON, 2002). Proporciona ao aluno um envolvimento num estudo profundo e exaustivo de um ou poucos objetos, de maneira que permita seu amplo e detalhado conhecimento (GIL, 2007).

Um estudo de caso é uma história de um fenômeno passado ou atual, elaborada a partir de múltiplas fontes de provas, que pode incluir dados da observação direta e entrevistas sistemáticas, bem como pesquisas em arquivos públicos e privados (VOSS; TSIKRIKTSIS; FROHLICH, 2002). É sustentado por um referencial teórico, que orienta as questões e proposições do estudo, reúne uma gama de informações obtidas por meio de diversas técnicas de levantamento de dados e evidências (MARTINS, 2008).

92

RELEDUC | ISE | v. 2 | n. 2 | ago. 2019 
Para tanto, as atividades foram desenvolvidas no ambiente escolar, ora utilizando a sala de aula, ora a área externa da escola.

Em um primeiro momento, os alunos tiveram contato com a história da publicidade durante as aulas do componente Administração de Marketing, que compõe a grade curricular do curso Técnico Integrado ao Médio em Administração das escolas técnicas de uma instituição do governo do Estado de São Paulo. Dentro desse contexto os alunos aprendem sobre a história da comunicação de massa, e encontram na figura de José Abelardo Barbosa de Medeiros, o precursor e principal referência da comunicação de massa televisiva no Brasil.

Após a explanação, com o propósito de elaborarem uma sala temática para um evento interno da escola denominado feira das profissões, a sala de 40 alunos foi dividida em 2 grupos. Após realizarem um levantamento sobre a propaganda no contexto brasileiro, cada grupo selecionou uma peça publicitária televisa veiculada nas décadas de 1980 e 1990.

Em um terceiro momento estudaram o contexto histórico da propaganda da época e elaboraram vídeos, tendo eles próprios como atores, fazendo uma releitura para os dias atuais, adaptando a linguagem, vestimentas e contextos culturais. As propagandas selecionadas foram: Me dá um beijo, do chocolate Laka da Lacta e Tio da Sukita, do refrigerante Sukita.

Por último, os alunos ornamentaram a sala de aula para receber os visitantes externos durante a realização da feira de profissões da unidade escolar, para tanto, reproduziram o programa "Cassino do Chacrinha", dando a devida importância a história do maior apresentador de um programa de auditório que o Brasil já teve.

\section{RESULTADOS E DISCUSSÃO}

A proposta da presente atividade surgiu diante da necessidade de se elaborar uma sala temática para a apresentação dos trabalhos desenvolvidos nos cursos técnicos da unidade de ensino, em um evento que recebe visitantes externos denominado ExpoEtec.

Os conceitos teóricos sobre a história e evolução da propaganda fazem parte do plano de curso do Curso Técnico em Administração Integrado ao Ensino Médio e são ensinados aos alunos durante a explanação das diferenças entre comunicação institucional e publicitária.

Com os conceitos teóricos trabalhados em aula e a proposta de se elaborar a sala temática, surgiu a ideia de utilizar a Aprendizagem Baseada em Projetos na execução da atividade, considerando o fato dessa metodologia transferir ao aluno o poder da busca pelo conhecimento. 
Após a concepção dos principais conceitos os alunos foram divididos em 2 grupos, cada grupo selecionou 1 propaganda que marcou época compreendendo as décadas de 1980 e 1990. Os alunos realizaram pesquisas na internet para chegarem nas propagandas de maior destaque, uma condição imposta aos grupos era selecionar a propaganda que causaria maior impacto após a releitura, onde os alunos e o próprio público conseguissem enxergar as diferenças culturais, de linguagens, vestimentas e conceitos que se passava antigamente em relação as comunicações dos dias atuais.

Após a seleção e aprovação do docente, os alunos desenvolveram um roteiro de como seria a propaganda adaptada para a realidade atual, estudando com isso os conceitos trabalhados nas peças publicitárias antigas e propondo uma adaptação para a realidade vivida por eles nos dias atuais, nesse momento desenvolvem o senso crítico em relação as mudanças ocorridas no decorrer dos anos, analisando o impacto que as sanções impostas pelo Conselho Nacional de Autorregulamentação Publicitária (CONAR) causou nas atividades publicitárias e consequentemente na preservação da ética e o respeito entre as marcas.

Com as finalizações dos roteiros e scripts, os alunos assumem o papel de atores nas produções dos vídeos, conhecendo uma realidade cultural e de costumes que não presenciaram e só conhecem pelos fatos narrados por familiares ou assistidos por vídeos.

A propaganda "Me dá um beijo" do chocolate Laka da Lacta tem como ator dois adolescentes, aparentando entre 12 e 14 anos, o menino chega na casa da menina que está se arrumando e pensando nele e aperta a campainha, ela pede que ele aguarde enquanto termina de se arrumar, após um certo tempo de espera, o menino come o chocolate Laka que estava guardando para a menina, quando ela atende a porta o menino fala "- trouxe uma Laka pra você”, ela responde, “- cadê?”, e ele dá um beijo nela com gosto do chocolate, após essa cena, ela pede mais um pedacinho. No contexto atual, a propaganda não poderia trabalhar com dois adolescentes se beijando, algo comum para a década de 1980, onde crianças e adolescentes eram mais expostos ao apelo publicitário. A releitura apresentou o mesmo contexto, porém os atores apresentam a aparência de 18 a 20 anos e o encontro acontece em uma praça pública, pois, nos dias atuais em início de namoro, o encontro não acontece em casa e sim em locais de convívio social do jovem. Outro fator de destaque foi a vestimenta, enquanto que na propaganda original os adolescentes vestiam roupas de pessoas adultas, na releitura eles utilizaram roupas próprias do público jovem. 
Para a propaganda intitulada "Tio da Sukita" os alunos trabalharam um conceito completamente diferente e atual. A propaganda original veiculada na década de 1990 se passa em um prédio, onde um senhor, solteiro, aparentando 50 anos percebe que no apartamento de cima ao seu está acontecendo uma festa com som alto e muita curtição, ele se troca e vai até o apartamento, apertando a campainha, ele é atendido por uma jovem, bonita e moderninha aparentando 20 anos bebendo uma Sukita, o senhor começa a puxar conversa com ela e ela sem tirar o canudinho da boca responde com "hãhã", até que em determinado momento ela diz: “- Ah tio desculpa, o som tá alto né?” e fecha a porta, nesse momento entra um efeito sonoro e uma locução dizendo: “-quem bebe Sukita não engole qualquer coisa”. Nessa propaganda os alunos interpretaram um posicionamento cultural da época, pois ainda existia um preconceito quanto a questão do namoro entre pessoas com grande diferença de idade. $\mathrm{Na}$ releitura, os alunos simularam uma festa que acontecia em uma casa, quando o vizinho, representado pelo "Tio da Sukita" aperta a campainha e começa a conversar com a menina bonita e moderninha, ao invés dela fechar a porta na cara dele, o chama para entrar e curtir a festa.

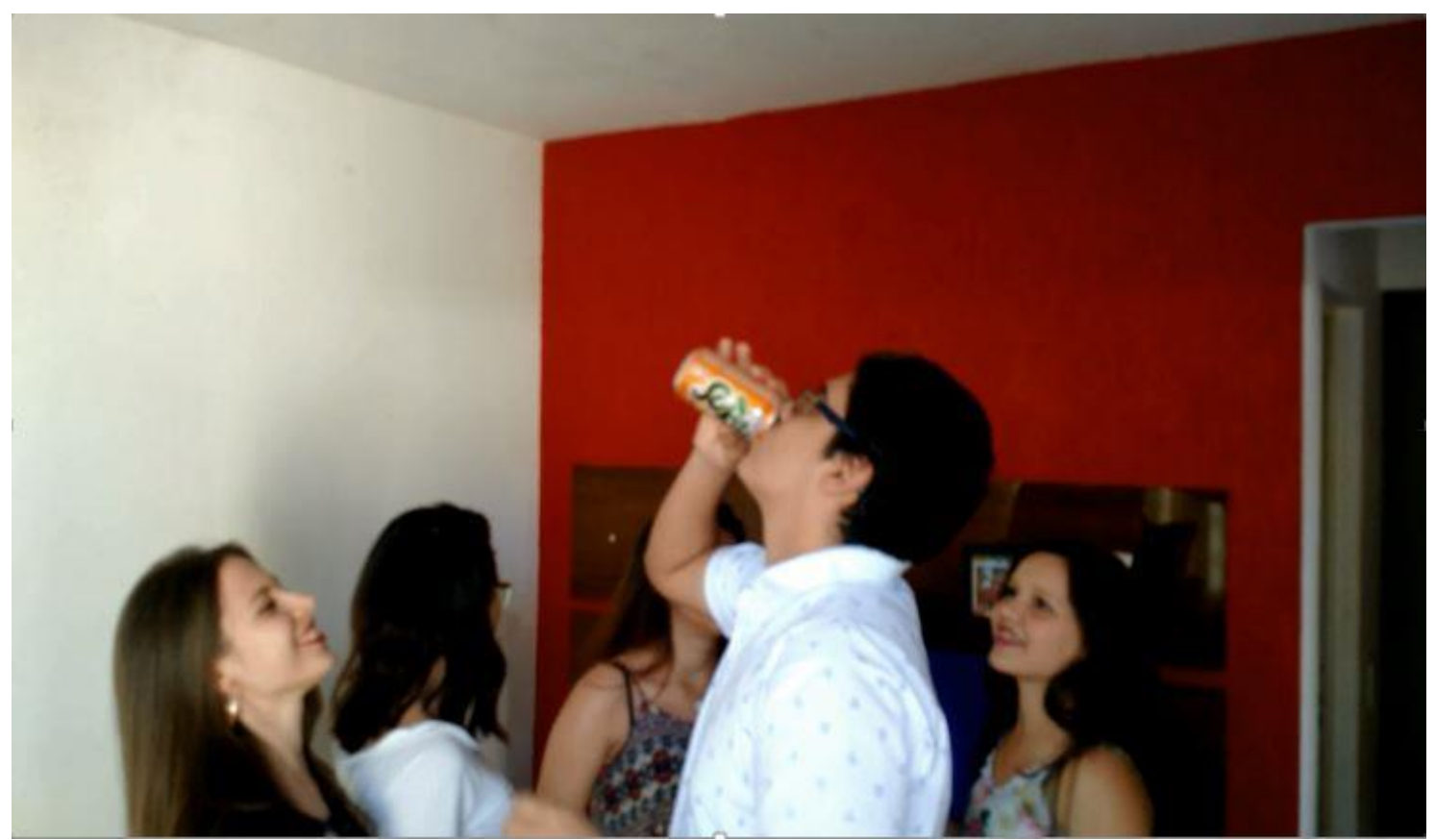

Imagem 1 - Captura de imagem do vídeo da releitura da propaganda da Sukita

Fonte: própria do autor, 2018

Os resultados dos trabalhos desenvolvidos, bem como a explanação das releituras e observações feitas pelos alunos foram apresentados na sala temática intitulada "A história da 95

RELEDUC | ISE | v. 2 | n. 2 | ago. 2019 
propaganda no Brasil através dos olhos do Velho Guerreiro, o Chacrinha" durante a feira de profissões realizada no ambiente escolar. Os demais alunos e visitantes externos puderam conhecer a história da propaganda televisiva brasileira por meio da exposição de vídeos e explicação dos conceitos publicitários pela linha do tempo entre as décadas de 1960, 1970, 1980, 1990, 2000 e atuais. Também foi abordado a história do Velho Guerreiro, onde os presentes puderam contemplar trechos do programa "Cassino do Chacrinha" exibido pela Rede Globo de Televisão

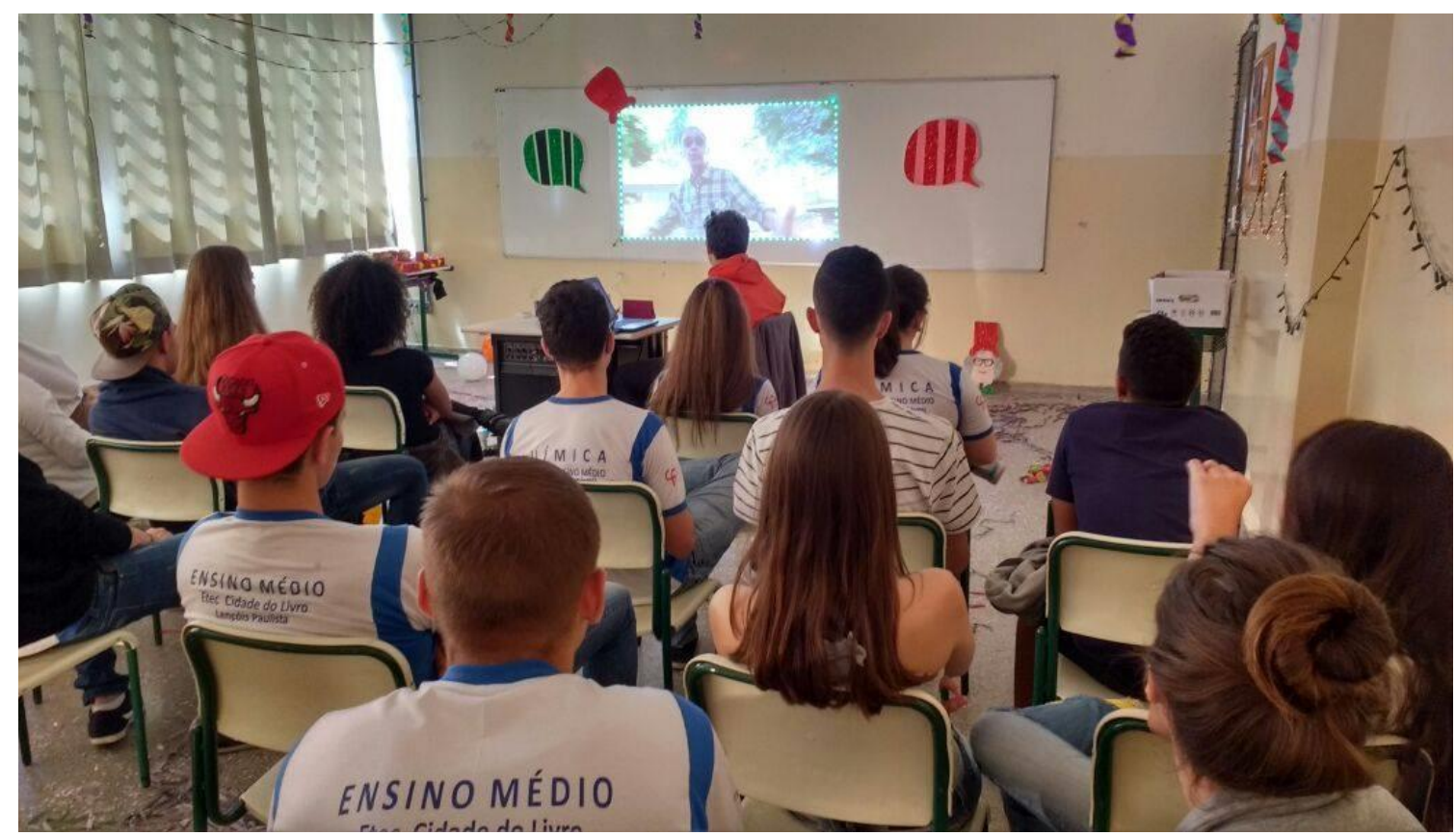

Imagem 2 - Reprodução do Cassino do Chacrinha durante feira escolar Fonte: própria do autor, 2018

\section{CONSIDERAÇÕES FINAIS}

Com os resultados obtidos conclui-se que a Aprendizagem Baseada em Projetos pode ser uma metodologia eficiente na diversificação das práticas pedagógicas, principalmente considerando o contexto tecnológico que presenciamos e pelo fato de colocar o aluno como ator da sua própria aprendizagem.

A adaptação de conteúdos discutidos em sala de aula se faz necessário diante da realidade que o aluno encontra em seu ambiente externo, ou seja, as práticas pedagógicas tradicionais devem ser revistas como forma de proporcionar aos alunos uma vivência mais

$$
\text { RELEDUC | ISE | v. } 2 \text { | n. } 2 \text { | ago. } 2019
$$


próxima de seu convívio social, familiar e profissional. A Aprendizagem Baseada em Projetos proporciona ao aluno a experiência de construir o conhecimento de forma colaborativa, incentivando a busca pelo conhecimento.

A elaboração de salas temáticas e participação dos alunos em feiras de ciências e eventos, tanto internos quanto externos, é um fator de extrema importância para o aluno, pois nessas atividades observa-se o engajamento e os resultados dos trabalhos em equipe.

É fundamental para o professor adaptar esse conteúdo para abordar de forma diferenciada o aluno em sala de aula, pois diante de tanta tecnologia e atrativos que encontramos hoje as antigas práticas pedagógicas se tornam obsoletas nesse processo.

Considera-se também que o uso da Aprendizagem Baseada em Projetos não deve ser adotada como prática constante, pois em pouco tempo se tornarão desinteressantes para o aluno, mas sim utilizadas em atividades esporádicas, levando-se em conta a diversificação das atividades pedagógicas.

\section{REFERÊNCIAS}

BARBOSA, E.F.; MOURA, D.G. B. Tec. Senac, Rio de Janeiro, v. 39, n.2, p.48-67, maio/ago. 2013.

BERBEL, N.A.N. As Metodologias Ativas e a Promoção da Autonomia de Estudantes. Semina: Ciências Sociais e Humanas. Londrina, v. 32, n. 1, p. 25-40, 2011.

BLIKSTEIN, P. O mito do mau aluno e porque o Brasil pode ser o líder mundial de uma revolução educacional. 25 jul. 2010. Disponível em:

$<$ http://www.blikstein.com/paulo/documents/books/Blikstein-

Brasil_pode_ser_lider_mundial_em_educacao.pdf>. Acesso em: 02 mar. 2019.

CERETTA, S. B; FROEMMING, L. M. Geração Z: Compreendendo os Hábitos de

Consumo da Geração Emergente. Revista Eletrônica do Mestrado Profissional em

Administração da Universidade Potigua. Ano III, n. 2 - abr./set, 2011.

GIL, A. C. Métodos e Técnicas de Pesquisa Social. 5 ed. São Paulo: Atlas, 2007.

IRALA, E.A.F. A comunicação mediada por computador no ensino-aprendizagem da língua inglesa: uma experiência com o programa AMANDA de discussões eletrônicas. Curitiba, 2005. 250 f. Dissertação (Mestrado em Educação) - Programa de Pós-Graduação em Educação, Pontifícia Universidade Católica do Paraná. 
MARTINS, G. A. Estudo de caso: uma reflexão sobre a aplicabilidade em pesquisas no Brasil. Revista de Contabilidade e Organizações, v. 2, n. 2, p. 9-18, jan./abr., 2008.

MAURER, A.L. As Gerações Y e Z e suas Âncoras de Carreira: contribuições para a gestão estratégica de operações. Rio Grande do Sul, 2013, 122f. Dissertação (Mestrado Programa de Pós-graduação em Administração, Mestrado Profissional). Universidade de Santa Cruz do Sul.

As Gerações Y e Z e suas Âncoras de Carreira: contribuições para a gestão estratégica de operações. Rio Grande do Sul, 2013, 122f. Dissertação (Mestrado - Programa de Pós-graduação em Administração, Mestrado Profissional). Universidade de Santa Cruz do Sul.

MORAN, J.; BACICH, L. Metodologias Ativas para uma Educação Inovadora: uma abordagem teórico-prática. 1 ed. São Paulo: Penso, 2018.

OLIVEIRA, M.F. Metodologia científica: um manual para a realização de pesquisas em Administração. Disponível em https://adm.catalao.ufg.br/up/567/o/Manual_de_metodologia_cientifica_-_Prof_Maxwell.pdf.

PATTON, M. G. Qualitative Research and Evaluation Methods, 3 ed. Thousand Oaks, CA: Sage, 2002.

VOSS, C.; TSIKRIKTSIS, N.; FROHLICH, M. Case research in operations management. International Journal Of Operations \& Production Management, v. 22, n. 2, p. 195-219, 2002. 